\title{
Elogio y sátira de la autoridad en el Perú virrreinal: la Loa al corregidor Valdivieso, una pieza desconocida de la ciudad de Piura (1775)
}

\section{Laud and Satire of the Authority during Peruvian Viceroyalty. the Loa al corregidor Valdivieso, an Unknown Piece from the City of Piura (1775)}

\section{Manuel Prendes Guardiola}

Universidad de Piura

PERÚ

manuel.prendes@udep.pe

[Hipogrifo, (issn: 2328-1308), 1.2, 2013, pp. 95-123]

Recibido: 18-06-2013 / Aceptado: 15-10-2013

DOI: http://dx.doi.org/10.13035/H.2013.01.02.10

Resumen. El presente trabajo da a conocer la existencia de una pieza de teatro breve representada en 1775 durante las fiestas por la toma de posesión de Matías de Valdivieso como corregidor de Piura. Previamente a la transcripción del texto, resume y comenta su contenido. Identifica sus características como típicas del género de la loa cortesana post-calderoniana, concebida no como un discurso laudatorio sino como toda una «comedia en miniatura». Asimismo, realiza una aproximación a las circunstancias en que se representó la loa y que explican su conservación en las actas de un proceso judicial por injurias contra ciertas autoridades piuranas.

Palabras clave. Siglo XVIII, loa, virreinato del Perú, Piura, teatro colonial.

Abstract. The present work states the existence of a short theatrical piece represented in 1775 during the celebrations for the coming to power of Matías de Valdivieso as corregidor (crown official) of Piura. Prior to the transcription of the text, it summarizes and comments its contents, and identifies its features as typical of the post-Calderon courtier loa (introductory piece) gender, conceived not as a laudatory discourse but as a «miniature comedy». Also, it conducts an approximation to the 
circumstances in which the loa was represented and which explain its conservation in records of a judicial process because of insults against in Piura's authorities.

Keywords. 18th Century, Loa, Peruvian Viceroyalty, Piura, Colonial Theater.

\section{EL PROCESO POR LA LOA AL CORREGIDOR VALDIVIESO}

El género teatral de la loa, que conoció su mayor desarrollo literario durante el esplendor de la literatura áurea del siglo XVII, experimenta un periodo de declive a lo largo de la centuria siguiente. En primer lugar, el común al conjunto de la literatura barroca hispánica, una vez desaparecidos sus máximos talentos (Calderón de la Barca, sor Juana Inés de la Cruz) sin dejar sucesores de la misma altura. En segundo, el ocasionado por la entronización de la dinastía borbónica, que habría de conllevar un cambio en los «mecanismos de afirmación política de la figura del monarca» ${ }^{\top}$. A consecuencia de dicho cambio, a principios del XVIII la loa se vería desplazada de la Corte, donde había alcanzado su mayor desarrollo como «comedia en miniatura» ${ }^{2}$ y relegada a «esporádicas manifestaciones en el marco de las casas nobles particulares, que hallarán en este tipo de código una forma de afirmación distintiva de su rango» ${ }^{3}$.

Tan lejos del siglo áureo del teatro español como en 1775, y de los núcleos del poder de la monarquía como en la ciudad de San Miguel de Piura, al norte del Perú, la toma de posesión del corregidor Matías José de Valdivieso y Céspedes sirvió para la representación de hasta ocho comedias. Una de ellas, El falso nuncio de Portugal (posiblemente la del mismo título de José de Cañizares), se representó públicamente el 8 de mayo precedida de una Loa en celebración del general don Matías de Valdivieso, corregidor de la ciudad de Piura. Esta pieza de teatro breve ha tenido la fortuna de conservarse gracias a un suceso no tan afortunado: la denuncia de que fue objeto a causa de sus alusiones satíricas hacia ciertas autoridades de la ciudad.

Aunque en el texto de la loa no se citaran nombres en concreto, se dieron por aludidos en razón de su dignidad el Alcalde Ordinario D. Miguel Serafín del Castillo y el Depositario General Felipe González Carrasco (precursor de Castillo como Alcalde). De este modo, ya terminados los festejos se dio orden de arresto contra los cómicos, un grupo de muchachos (solo Domingo Córdova, que representó el papel del Mérito, era mayor de edad) que habían recibido el texto de manos del sacerdote José Domingo de Vargas, en cuya casa habían tenido lugar los ensayos. Los jóvenes actores se dieron a la fuga y tan solo fue prendido Juan Jorge de la Fuente y Vargas (o Fuentes de Vargas), alias «el Guacho», mozo menor de dieciocho años

\footnotetext{
1. Farré, 2002, pp. 775 .

2. La expresión es de Alfonso Méndez Plancarte, «Notas», Obras completas de Sor Juana Inés de la Cruz, III, México, Fondo de Cultura Económica, 1995, pp. LII-LIV, y utilizada por Rice, 2012, pp. 88, 89 y 104. 3. Farré, 2002, p. 776.
} 
que era pupilo del padre Vargas y, significativamente, había representado en la loa el papel del Placer, cuyas palabras fueron las que provocaron el escándalo.

Los fondos del Archivo Arzobispal de la archidiócesis de Piura, en actual proceso de clasificación, albergan el expediente del proceso: 68 hojas bajo el título de Miguel Serafín del Castillo, Alcalde Provincial de la Santa Hermandad y Ordinario de Primer Voto por su majestad en Piura, solicita desagravio por parte del presbítero José Domingo Vargas"; fechadas entre el 14 de junio de 1775 y el 22 de mayo de 1776. En ella se recoge, previo al texto completo de la loa (hojas 5r-10r), un alegato en defensa de los imputados por ser menores de edad e irresponsables del contenido del texto que representaron (a cuyo alcance satírico quita importancia). Sigue la acusación por parte del alcalde del Castillo, quien remitiéndose a las Partidas considera tan culpable a quien difunde un libelo como a quien lo escribe, y enumera las alusiones satíricas de la loa:

se les hizo de decir y dijeron las más feas injurias, baldoneos y desprecio contra los jueces de esta ciudad que han sido y al presente son, denigrando su conducta con los más insolentes dicterios, tratándolos de ignorantes apasionados, y que sus sentencias eran diabólicas y solo propias para darlas en los infiernos; también se hizo salir en la loa a la Envidia con el ánimo de denigrar en esta a personas su dignidad y empleo público calumniosamente... ${ }^{5}$

Seguirán diversos testimonios: los de Jorge Fuentes de Vargas y los progenitores de tres de los cómicos aún en paradero desconocido, más el de un vecino espectador y el de Juan José Jaramillo, portero del Cabildo que rehusó participar en la representación. En vista de que todos los testimonios apuntan a la autoría del José Domingo de Vargas, se ordena cesar la persecución de los actores y el Alcalde Ordinario emprende las gestiones con el Arzobispado de Trujillo para que el clérigo sea juzgado ante un tribunal eclesiástico. Los últimos documentos recogen las recusaciones del Alcalde Ordinario de Piura contra los magistrados designados por Trujillo, incluyendo amargas quejas contra la lentitud y parcialidad de las autoridades eclesiásticas.

\section{LA CRÍTICA SOCIAL DE LA LOA EN SU CONTEXTO}

Las piezas de teatro festivo y laudatorio no estaban exentas de una dimensión crítica, de singular alcance puesto que se solían interpretar en la misma presencia de los poderosos. Robin Ann Rice, citando a Ignacio Arellano, habla de cómo géneros como la loa o el auto sacramental integran «las crisis, las preocupaciones y as-

4. En lo sucesivo, me referiré a este documento como Desagravio. Hago constar aquí mi agradecimiento por la comunicación de su existencia al profesor Pável Elías Lequernaqué, así como a las profesoras Djanira Aparicio y Shirley Cortez por el apoyo en la transcripción e interpretación, y a la magíster Yanina Correa por facilitarme el trabajo en el Archivo.

5. Desagravio, 22 de mayo de 1775, fol. 13r-13v. Las alusiones se refieren a los vv. 651 y 667 de la loa, reproducida en el Apéndice final de este artículo. 
piraciones [...] de su tiempo»6: un personaje como la Plebe, en una de las loas de sor Juana Inés de la Cruz, podía ser visto como una encarnación de la lealtad al monarca, pero al mismo tiempo de potencial insurrección? ${ }^{7}$. Por mencionar otro interesante ejemplo novohispano, aunque en una circunstancia posterior y más inofensiva, Frederick Luciani analiza la crítica al sistema de escolarización conventual presente en una máscara que las alumnas internas representaron en 1756, ante la visita al convento de San Jerónimo del virrey marqués de las Amarillas ${ }^{8}$.

En el contexto social peruano que nos ocupa, no era poca la conflictividad: el cargo de corregidor que asumía Matías de Valdivieso, frecuentemente ocupado por miembros de importantes familias de hacendados ${ }^{9}$, solía revestir a su titular de una gran impopularidad, sobre todo entre los más humildes, debido a abusos autorizados por la misma corona como el del «reparto mercantil» ${ }^{10}$, que convertían el corregimiento en un símbolo popular del mal gobierno. La desmedida codicia y pingües ganancias de los corregidores piuranos era recordada en aquella época por el padre Mario Sicala, jesuita italiano de la provincia de Quito que había visitado Piura el año $1767^{11}$.

Sin embargo, cabe aquí la posibilidad de que detrás de la adulación al poderoso, connatural a la loa desde su configuración como género cortesano en el siglo anterior, hubiera una confianza real en que la nueva autoridad pusiera coto a la injusticia que tan poco ejemplarmente campaba en la ciudad. Valdivieso, desde luego, parece haberse sentido halagado por la buena propaganda que le hizo la loa frente a las otras dignidades locales, como probaría su pasividad a lo largo de todo el proceso e incluso, según protesta del alcalde ordinario Miguel del Castillo, de su complicidad en la difusión popular del texto ${ }^{12}$.

\section{CARACTERIZACIÓN GENÉRICA Y ESTRUCTURA INTERNA DE LA LOA A VALDIVIESO}

El texto de José Domingo de Vargas adopta forma de «loa competencial» ${ }^{13}$, en la que varios personajes alegóricos (en este caso la Justicia, la ciudad de Piura, el Placer, el Mérito y la Envidia) disputan y argumentan aspirando obtener un dicta-

\footnotetext{
6. Rice, 2012, p. 89. La cita remite a Ignacio Arellano, Estructuras dramáticas y alegóricas en los autos de Calderón, Pamplona/Kassel, Universidad de Navarra/Reichenberger, 2001, p. 11.

7. Rice, 2012, pp. 98-99.

8. Luciani, 2008.

9. Reyes Flores, 1999, p. 59. Matías de Valdivieso y Céspedes era natural de la misma ciudad de Piura, militar y también contador y escribano de Su Majestad (1756-1760), además de abogado de las audiencias de Lima y Quito. Ocupó el corregimiento de Piura entre 1775 y 1780, el antepenúltimo antes de que la institución fuera sustituida en 1783 por el nuevo sistema de intendencias.

10. El reparto consistía en el monopolio por parte del corregidor de la venta a indios de mercancías que, con frecuencia, les resultaban inútiles y abusivamente caras. Es significativo que, como ha observado Jürgen Golte (1980), los lugares donde más se extendieron estas prácticas fueron los mismos en que mayor intensidad alcanzó, una década después, la rebelión de Túpac Amaru II.

11. Sicala, Descripción, p. 533

12. Desagravio, 13 de diciembre de 1775 , fol. $65 \mathrm{v}-66 \mathrm{r}$

13. Zugasti, 2008, p. 311
} 
men favorable. Del mismo modo, bien se le puede aplicar la denominación genérica de «genuflexión literaria», acuñada por Suárez Radillo y que utilizan Andrés Eichmann ${ }^{14}$ o Miguel Zugasti, quien las define como «piezas dramáticas escritas para el halago de algún poderoso, y nadie más poderoso en los ambientes de la colonia que el virrey» ${ }^{15}$. Podemos añadir aquí cómo en espacios notoriamente más modestos, nada cortesanos, hay siempre un poderoso a quien celebrar: el corregidor en el ámbito provincial que nos ocupa o bien, entre las dignidades menores de la administración colonial y por esa misma época, el Mayordomo del limeño hospital de San Andrés (asunto de la Loa a D. Pedro del Villar escrita por Francisco del Castillo, «el Ciego de la Merced») ${ }^{16}$.

Domina en el texto de nuestra loa, también en palabras de Miguel Zugasti, «el panegírico y la hiperbólica semblanza del festejado», si bien en el caso que aquí nos ocupa no habrá referencias a la familia ni al linaje de Valdivieso. Por último, también en esta loa «teatro, música, canto, escenografía, intereses políticos y adulación se funden en un todo indisoluble» ${ }^{17}$, aunque con recursos evidentemente más pobres que los de la fiesta cortesana, como corresponde al rango subalterno tanto del festejado como de la ciudad que organizaba los fastos en su honor.

El argumento y la estructura de la Loa a Valdivieso presentan alguna diferencia con respecto al esquema general de la loa palaciega descrito por Judith Farré. El debate de méritos entre los personajes alegóricos, como veremos, no busca aquí «decidir a partir de su definición alegórica para así conseguir la preeminencia en la celebración ${ }^{18}$. Más bien, en razón de dichas definiciones, todos elogiarán sin necesidad de previo acuerdo las virtudes de Matías de Valdivieso, frente a la Envidia que es el único personaje discordante. Sí existe, sin embargo, la «yuxtaposición de méritos» de los participantes, que simboliza la grandeza del personaje celebrado.

Robin Ann Rice, sumando los elementos funcionales observados por Farré a la ya mencionada noción de la loa como microcomedia (última innovación sobre el género a partir de las loas palaciegas y sacramentales de Calderón) ${ }^{19}$, aplica un esquema de división en actos a las loas de sor Juana Inés de la Cruz que resulta muy útil para reconocer y analizar la estructura de nuestra loa piurana. En el caso de la pieza de José Domingo de Vargas, la división resulta evidente gracias al empleo de la música y las variaciones en rima y métrica, si bien tampoco se corresponde exactamente con la división en nudo-desenlace-elogio que observa Rice en los tex-

\footnotetext{
14. Eichmann, 2008, p. 286. Uno y otro citan a citan a Carlos Miguel Suárez Radillo, El teatro barroco hispanoamericano II, Madrid, Porrúa Turanzas, 1981, p. 385

15. Zugasti, 1997, p. 563.

16. Castillo, 1996, pp. 500-507.

17. Zugasti, 1997, p. 554

18. Farré, 2002, p. 777. También señala la frecuente presencia de «un juez mediador que demuestra la complementariedad simbólica de todas las propuestas festivas inicialmente enfrentadas». No obstante, en la Loa a Valdivieso el papel de la Justicia como personaje que dictamina el triunfo es notoriamente parcial.

19. Rice, 2012 , p. 88.
} 
tos que analiza ${ }^{20}$. Así pues, procederemos según esta división tripartita a resumir y comentar la Loa a Valdivieso.

\title{
Primer acto: planteamiento (vv. 1-256)
}

Escrito en romance con rima $i-a$. Unos versos cantados (vv. 1-12) anuncian a modo de argumento general que

\author{
Del Mérito a las razones \\ hoy atendiendo benigna, \\ al ilustre Valdivieso \\ ha de premiar la Justicia (vv. 1-4).
}

Entran en escena la ciudad de Piura y la Justicia «con corona y cetro»: la referencia de esta a su «sagrado alcázar» (v. 109), donde acuden los demás personajes, será el único indicio de ambientación escénica proporcionado en el texto. Uno y otro personaje se rinden mutuos elogios: en primer lugar, Piura encomia a la Justicia como atributo divino que premia a los sabios y a los héroes (vv. 20-28, con referencia a los «alumnos de Minerva y Marte» que parece aludir al nuevo corregidor, jurista y militar), que posee la función ejemplar de valorar por igual las hazañas de los nobles y las indignas acciones del vulgo, para premiar a quien lo merece.

La Justicia responde a esta captatio benevolentiae con una extensa alabanza a la ciudad de Piura: empieza por su «antigüedad y nobleza» (v. 55) ${ }^{21}$ y su preeminencia sobre otras ciudades de las Indias. En su cultura, es equiparada a la misma Atenas, por más que aquí no se traiga a colación más nombre que el del mismo Valdivieso, piurano de origen:

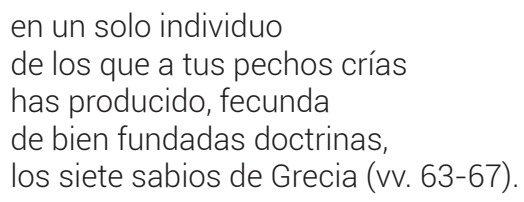

Asimismo, la fertilidad de «paraíso terrenal» (v. 69) y buen clima que reinan en Piura son tales que nadie muere en su suelo más que porque es «condición de lo mortal» (v. 81) que la vida tenga fin ${ }^{22}$. Por todo ello, afirma estar dispuesta a escuchar la petición de la ciudad «con placer» (v. 101). Esta expresión motiva la sali-

\section{Rice, 2012, p. 90}

21. San Miguel de Piura fue, efectivamente, la primera ciudad fundada por los españoles al emprender la conquista del Perú, en 1532.

22. Según el testimonio del padre Sicala en aquella misma época, el seco y caluroso clima de Piura resultaba altamente saludable. Además, tenía gran fama la atención hospitalaria del convento de los padres betlemitas, el cual recibía enfermos de lugares tan apartados como «Panamá, Guayaquil, Quito, Popayán, Chile y tal vez de toda la América Meridional» (Sicala, Descripción, p. 537). La fertilidad del suelo piurano fue también descrita con asombro por el jesuita (pp. 538-539, 548-552). 
da a escena del Placer, «vestido graciosamente», pues cree haber sido llamado ${ }^{23}$. Reprendido por la Justicia a causa de su entrada intempestiva, se identifica enumerando varios sinónimos e imágenes asociadas a su nombre, dentro del campo semántico de la fiesta, la celebración y los goces sencillos:

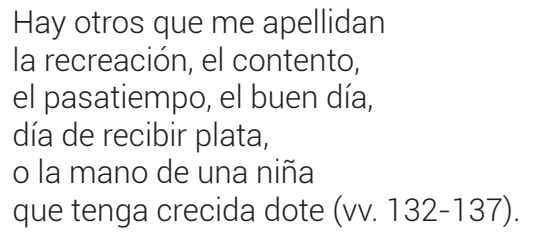

Finalmente, Piura hace callar al Placer, quien acepta de mala gana (vv. 166-167: "Sí callaré, como en misa, / aunque rabio por hablar») y a lo largo de la representación no dejará de transgredir el mandato. En su papel de gracioso, el Placer se distinguirá por su la relajación de la solemnidad con que habla y se conduce el resto de los personajes. De ese modo, como veremos, replica a sus interlocutores o comenta la acción en cómicos apartes, además de acudir a un registro coloquial de habla: «mentando al ruin de Roma» (v. 103), «no es tan fiero el león» (v. 299), «vaya a cardar» (v. 524), «va dada al diablo» (v. 584), «aunque me maten» (v. 620), «cada hijo de vecino» (v. 635)...

Llamado al orden el Placer, la ciudad emprende a continuación su panegírico de Matías de Valdivieso: recurre a metáforas mitológicas como la de «Atlante» que sostiene la provincia (vv. 169-170; el Placer la repetirá en v. 628) y «Apolo / cuya gran sabiduría / en cátedra de milagros / lección de prodigios dicta» (vV. 173-176), y también lo reclama como «parte suya» y «criado a mis pechos» (vv. 190-191). Alude a sus distinguidos servicios como oficial real y a cómo, en el momento en que se disponía a resignar esa plaza, le llegó el nombramiento de corregidor, por el cual Piura lanza vivas al rey Carlos III «que así premia y dignifica / sus muy leales vasallos» (vv. 218-219). Sin embargo, Valdivieso, como sabio, busca la quietud y el alejamiento de los negocios públicos, de manera que la ciudad pide a la Justicia que le persuada de aceptar el corregimiento, «que aunque a su humildad le sirva / de carga y peso, es un peso / con que a todos nos alivias» (vv. 238-240).

La Justicia demora su sentencia hasta escuchar a quien pueda contradecir el alegato de la ciudad de Piura, a lo que esta replica que solo la envidia sería capaz de tal cosa, y aun en este caso «ya vendrá quien la resista» (v. 256). Quedan, de ese modo, convocados para su inminente salida a escena dos nuevos personajes, la Envidia y el Mérito.

Como puede comprobarse, este primer acto de la Loa a Valdivieso estaría ocupado, a falta de debate entre los personajes sobre sus propios méritos, por la presentación de tres de ellos. Asimismo, queda planteado el caso sobre el que se dis-

23. En la antes mencionada Loa a don Pedro del Villar, de índole parecida a la que aquí nos ocupa, es asimismo el Regocijo quien hace el papel de gracioso y, del mismo modo, entra inopinadamente al escenario y al festejo (Castillo, 1996, p. 503). 
cutirá en el segundo momento de la representación: los méritos de Valdivieso para ocupar el corregimiento de Piura.

\section{Segundo acto: nudo y desenlace (vv. 257-550)}

En romance con rima e-e, y nuevamente abierto por una música que convoca al Mérito, anuncia su triunfo (vv. 257-260) y le anima a no temer a la Envidia (vv. 267270). Como hemos indicado anteriormente, este acto se caracterizará no tanto por la conciliación entre varios personajes simbólicos en disputa, sino en el común acuerdo de todos contra la Envidia.

Esta se jacta, en el momento de su aparición, de no haberse rendido jamás ante la Justicia y el Mérito: en la constancia coincide la Envidia con la imagen que de este vicio proporcionan los emblemas de Cesare Ripa, de gran importancia en la iconografía barroca. Según este autor, la envidia «se pinta vieja porque, por decirlo con pocas palabras, larga y antigua enemistad con la virtud mantiene» ${ }^{24}$. Otra coincidencia, ahora visual, la hallamos en las palabras del Placer, quien comenta la apariencia de la Envidia y cómo no la encuentra tan horrenda, aunque esperaba ver «un demonio / más feo doscientas veces / que todos los diablos juntos» (vv. 295-297), según la pintan «mil retóricos Apeles» (v. 294) o autores del pasado. Sin embargo, le inspira compasión ver un «viborón» (v. 305) royéndole el pecho, imagen que asimismo presentaba Ripa ${ }^{25}$ y probablemente único detalle visible que el vestuario de los actores habría empleado para que la Envidia resultara reconocible.

El Mérito replica a la Envidia que solo ha sido vencido por ella cuando ha faltado la Justicia, ahora presente. Aun así, la Envidia alardea de su gran poder y de sus triunfos, de los que pone como ejemplo el haber dominado a Luzbel y provocado el pecado de Adán y Eva, entregados desde entonces «al imperio de la Muerte» (v. 362). La Justicia la interrumpe y pide a los litigantes que se ciñan al caso, es decir, den su parecer sobre si Valdivieso debe aceptar o no el gobierno de la ciudad y provincia. El Placer, rompiendo de nuevo su promesa de silencio, comenta en esta ocasión que, ante la calidad del homenajeado, tan solo el Mérito deberá tener algo que decir, destacando -en una primera invectiva contra la administración de la justicia en la ciudad de Piura ${ }^{26:}$

\section{Ripa, Iconología, p. 342}

25. «Mujer delgada, vieja, fea y de lívido color. Ha de tener desnudo el pecho izquierdo, mordiéndoselo una sierpe que se ciñe y enrosca apretadamente alrededor del pecho que decimos. A su lado se pondrá una Hidra, sobre la cual posará la mano» (Ripa, Iconología, p. 341). Otros autores, como Ovidio o Alciato, presentan en cambio a la envidia alimentándose de serpientes o coronada de ellas; sin embargo, coinciden en su fealdad como mujer lívida y consumida, o también bizca. La compasión que siente el Placer interpreta las imágenes tradicionales: la Envidia sufre un tormento constante y no halla satisfacción ninguna.

26. Los tres últimos versos, de hecho, son aparentemente olvidados por Jorge de Vargas «el Guacho» al recitar su papel de Placer en su primera declaración judicial del proceso (Desagravio, 26 de mayo de 1775 , fol. $21 \mathrm{r}-21 \mathrm{v})$. 


\author{
el beneficio que viene \\ a este noble vecindario \\ de que sus causas sentencie \\ un docto jurisperito, \\ sin que en ellas ya se mezcle \\ con dictámenes errados \\ tanto abogado zoquete (vv. 388-393).
}

La Justicia parece hacer caso al Placer, y cede la palabra al Mérito, quien pasa a detallar algunas de las prendas que enaltecen a Matías de Valdivieso. Empieza por su «claridad», tan grande que su corazón «parece hoguera» (vv. 414-415) donde enciende y lanza como flechas sus afectos, en nueva equiparación mitológica con el dios Cupido: en la cima de la apoteosis, declara que nadie puede dejar de amar a Valdivieso sin ganar «torpe nota de rebelde» (v. 422). Pondera luego su «prudencia» (v. 423), representada por las «balanzas de la discreción» (vv. 427-428) donde el general sopesa sus obras antes de ejecutarlas; también la «mansedumbre y paciencia» (v. 431) que templan como nieve el fuego de su gran celo (vv. 435-442); su erudición, demostrada en las Audiencias en que ha desempeñado su profesión y donde ha demostrado ser «animada biblioteca / de los derechos y leyes» (vv. 447448). Hay una última enumeración de cualidades: «desinteresado, atento, / compasivo, indulgente, / cristiano, noble y amable» (vv. 451-453), además de «guardar su fuero a cada uno» (v. 455) sin despreciar al pobre o esperar ganancias del rico, donde hallamos una nueva denuncia de las autoridades locales.

La Justicia se declara convencida por las razones del Mérito, ante el aplauso del Placer, quien no duda sin embargo que haya «necios» que pretendan oscurecer las glorias de Valdivieso «porque les duele» (v. 474). Llegado su turno, la Envidia es incapaz de alegar ningún demérito en contra del homenajeado, y más bien reconoce (en la línea de autores pretéritos como los ya citados) cómo a sus ojos «todos los bienes ofenden» (v. 480), afirmación que se ve amplificada por una serie de paralelismos que ejemplifican su resentimiento ante las bellezas de la naturaleza. La Justicia, lógicamente, desecha este discurso y otorga la victoria al Mérito y a Piura, manifestando el deseo de que Valdivieso permanezca siempre en el «solio» (v. 541) sin que lo derriben de él los vaivenes de la Fortuna.

\title{
Tercer acto: elogio (vv. 551-686)
}

A invitación de la Justicia, suena la Música para celebrar la victoria del Mérito (redondillas, vv. 551-558) y a continuación los personajes van recitando décimas con las que se retiran sucesivamente del escenario hasta dejar solo al Placer (vv. 559-618). La primera en desaparecer es la Envidia, quien recita dos décimas manifestando cómo a causa de su humillación parte a morir ${ }^{27}$ y es despedida burlonamente por el Placer. A continuación, el Mérito consagra a la Justicia sus laureles (imagen recurrente a lo largo de toda la loa) y parte a gozar de su triunfo; la Justicia,

27. Repárese en la hipérbole: antes la Envidia ha declarado ser poco menos que eterna, de modo que el triunfo de Valdivieso aparece como la victoria definitiva y universal del Mérito sobre ella. 
por su parte, felicita a Piura por su buen corregidor e insiste en la objetividad de su criterio; Piura, en respuesta, agradece a la Justicia en nombre de sus habitantes, con una imagen de ámbito sacro: «te ofrezco en aras del pecho / inciensos de gratitud» (vv. 617-618)

Queda el Placer solo en escena, lo que aprovecha para romper definitivamente su prohibición de hablar («he de hablar aunque me maten», v. 620) y abandonar el discurso en décimas para regresar al cómodo metro del romance (en a-e, vv. 619686), según él por no poderse «avenir / con la ley del consonante» (vv. 625-626). Al gracioso de la obra corresponde, por tanto, la loa propiamente dicha, es decir, el panegírico del personaje celebrado que dará fin a la representación. En su parlamento final apela directamente al nuevo corregidor como «ilustre jefe» $\mathrm{y}$ «Atlante» (vv. 627-628), lo felicita y manifiesta la alegría de toda la ciudad por su nombramiento, que ya no les hará temer

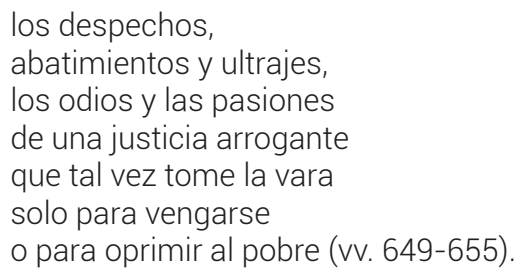

Estos versos, reiteradamente citados en la acusación levantada por el alcalde Miguel Serafín del Castillo, citados por testigos y, en cambio, «olvidados» por su recitante en su segunda declaración ${ }^{28}$, con su contenido de protesta, nos recuerdan no solo la ya mencionada carga crítica que podía admitir el género de la loa, sino cómo esta podía implicar directamente a su auditorio. No solo abordando una problemática conocida o padecida por este, sino dirigiéndose a él traspasando los límites del escenario (en lo cual radicaba el mismo origen del género) ${ }^{29}$, y permitiéndole identificarse con el personaje. El Placer, figura cómica de la loa, que habla a un público formado por nobleza y plebe (dato reiterado como agravante por la acusación a lo largo de todo el expediente) y en la que esta probablemente se reconocía, acaba constituyéndose, como lo llama José Iniesta Maestro, en «metáfora perfecta del espectador» ${ }^{30}$ al igual que otros personajes populares de la loa palaciega y sacramental del Barroco.

28. Desagravio, 1 de junio de 1775 , fol. $28 v-29 r$.

29. Un primer ejemplo de ello se encontraría también a poco de la salida del Placer a escena, al referirse en apariencia a la fiesta circundante: «El Placer soy, pues, y vengo / sin que toquen campanilla / a gozar de esta función / que, si no dicen mentira, / es una de las mejores» (vv. 153-157).

30. Citado en Sileri, 2004-2005, p. 262 (referencia a José Iniesta Maestro, Entre la retórica y la escena: construcción literaria y dramática de la loa en el siglo XVII, Memoria de licenciatura, Universidad de Valencia, 1986, p. 118). 


\section{CONCLUSIÓN}

La Loa en celebración del general don Matías de Valdivieso se nos presenta como una muestra tardía y muy canónica del género de la loa «calderoniana», concebida como una brevísima pieza teatral ya emancipada de la función de introducir la comedia que la sigue. El autor demuestra tener bien asumidas las convenciones del género, y asimismo haber cuidado perfectamente su organización como microcomedia. No se aprecia la misma perfección en cuanto a la métrica de los versos, en algunos de los cuales falla el ritmo octosilábico, o en cuanto a los esporádicos anacolutos gramaticales.

No resulta excepcional por sí misma, aunque sí como muestra de la evolución de la loa cortesana cuando el género ya había sido desplazado de la corte. El estar dedicada a una autoridad civil de provincias, además de explicar su pobreza escenográfica, hace pensar en cómo el texto se hubiera perdido irremediablemente, como tantos otros, de no ser por la intención satírica que el autor introdujo en sus textos. Su descubrimiento supone, en todo caso, un nuevo estímulo para la búsqueda en archivos «menores» de la época en busca de hallazgos semejantes.

Por lo que se refiere a la persecución legal que motivó la Loa a Valdivieso, a la que paradójicamente debemos agradecer su conservación ${ }^{31}$, es notable asimismo cómo la función política que a veces albergaba la loa palaciega del Barroco no ha desaparecido aún de esta obra epigonal, y que admite una dirección de abajo a arriba y no a la inversa. Al tiempo que se elogia y manifiesta lealtad al poderoso (el corregidor, como pudiera en otros textos análogos haber sido el virrey), se le manifiesta el descontento. Se demanda a los representantes del soberano, en este caso, una alianza con el pueblo frente a administradores indignos, lo cual integra la pieza en una tradición de exaltación monárquica de gran importancia para la misma comedia clásica española.

\section{BIBLIOGRAFÍA}

Castillo, Fr. Francisco del, Obra completa, ed. César A. Debarbieri, Lima, 1996.

Eichmann Oehrli, Andrés, «Textos dramáticos de la colección de manuscritos musicales de Sucre (Archivo nacional de Bolivia)», en Ignacio Arellano y José Antonio Rodríguez Garrido (eds.), El teatro en la Hispanoamérica colonial, Madrid/ Frankfurt am Main, Iberoamericana/Vervuert, 2008, pp. 275-294.

Farré, Judith, «A propósito de las metáforas y los tópicos panegíricos», AISO, Actas VI, Centro Virtual Cervantes, 2002, pp. 775-785.

Golte, Jürgen, Repartos y rebeliones. Túpac Amaru y las contradicciones de la economía colonial, Lima, Instituto de Estudios Peruanos, 1980.

31. Y que no sería el primer conflicto que involucrase, en la Piura del XVIII, autoridades y literatura: en el capítulo XI de Piura y el virreynato [sic], Reynaldo Moya (p. 11) da noticia de la excomunión en 1747 del corregidor Antonio de Matienzo con motivo de la representación de una comedia en su misma casa. 
Luciani, Frederick, «Fantasmas en el convento: una "máscara" en San Jerónimo (México, 1756)», en Ignacio Arellano y José Antonio Rodríguez Garrido (eds.), El teatro en la Hispanoamérica colonial, Madrid/Frankfurt am Main, Iberoamericana/Vervuert, 2008, pp. 259-273.

Miguel Serafín del Castillo, Alcalde Provincial de la Santa hermandad y Ordinario de Primer Voto por su majestad en Piura, solicita desagravio por parte del presbítero Josef Domingo Bargas, Piura, 14 de junio 1775-22 mayo 1776 [Archivo Arzobispal de Piura].

Moya, Reynaldo, Piura y el virreinato, [DOI www.galeon.com/piurayelvirreynato].

Reyes Flores, Alejandro, Hacendados y comerciantes. Piura-Chachapoyas-Moyobamba-Lamas-Maynas (1770-1820), Lima, Juan Brito/Universidad Nacional Mayor de San Marcos, 1999.

Rice, Robin Ann, «"Estando ausente Carlos, / ¿qué importa que las festivas voces le aplauden, si nada escucha?": las loas a los años del rey Carlos II de sor Juana Inés de la Cruz», Hipogrifo. Revista de literatura y cultura del Siglo de Oro, 1.1, 2013, pp. 87-104 [DOI http://dx.doi.org/10.13035/H.2013.01.01.07].

Ripa, Cesare, Iconología, trad. del italiano de Juan Barja y Yago Barja, trad. del latín y griego de Rosa Ma Mariño Sánchez-Elvira y Fernando García-Romero, pról. de Adita Allo Manero, Madrid, Akal, 1996 (2ª ed.), 2 vols.

Sicala, Mario, Descripción histórico-topográfica de la provincia de Quito de la Compañía de Jesús, Quito, Biblioteca Ecuatoriana Aurelio Espinosa Polit, 1994

Sileri, Manuela, «Apuntes sobre clasificación y evolución de la Loa: una propuesta», Etiópicas, 1, 2004-2005, pp. 243-270.

Zugasti, Miguel, «Un texto virreinal inédito: loa para la zarzuela También se vengan los dioses de Lorenzo de las Llamosas», en Unum et diversum. Estudios en honor de Ángel-Raimundo Fernández González, Pamplona, EUNSA, 1997, pp. 553-569.

- $\quad$ "Teatro recuperado en Charcas: dos loas olvidadas de fray Juan de la Torre (OSA) a la entrada del virrey Diego Morcillo en Potosí, 1716», en Ignacio Arellano y José Antonio Rodríguez Garrido (eds.), El teatro en la Hispanoamérica colonial, Madrid/Frankfurt, Iberoamericana/Vervuert, 2008, pp. 295-317. 


\title{
Apéndice: Loa en celebración del general don Matías de Valdivieso, corregidor de la ciudad de Piura
}

Hablan:

\author{
LA CIUDAD DE PIURA \\ EL PLACER \\ LA ENVIDIA \\ LA JUSTICIA \\ EL MÉRITO \\ MÚSICA
}

[Primer acto]

(Canta la música)

Del Mérito a las razones hoy atendiendo benigna, al ilustre Valdivieso ha de premiar la Justicia. Prevenid, bellos pensiles, prevenid, selvas sombrías, los laureles inmortales, las flores más peregrinas, y tejed una corona cuya hermosura florida sirva de honra al galardón y de baldón a la envidia.

(Salen la Ciudad de Piura y la Justicia, con corona y cetro ésta).

PIURA

Oh tú, beldad coronada, oh hermosura peregrina, honor del alto zafir,

blasón de la deidad misma,

tú, por cuyo recto juicio

y discreción exquisita se han regulado prudentes para premiar las lucidas acciones de sus alumnos, 


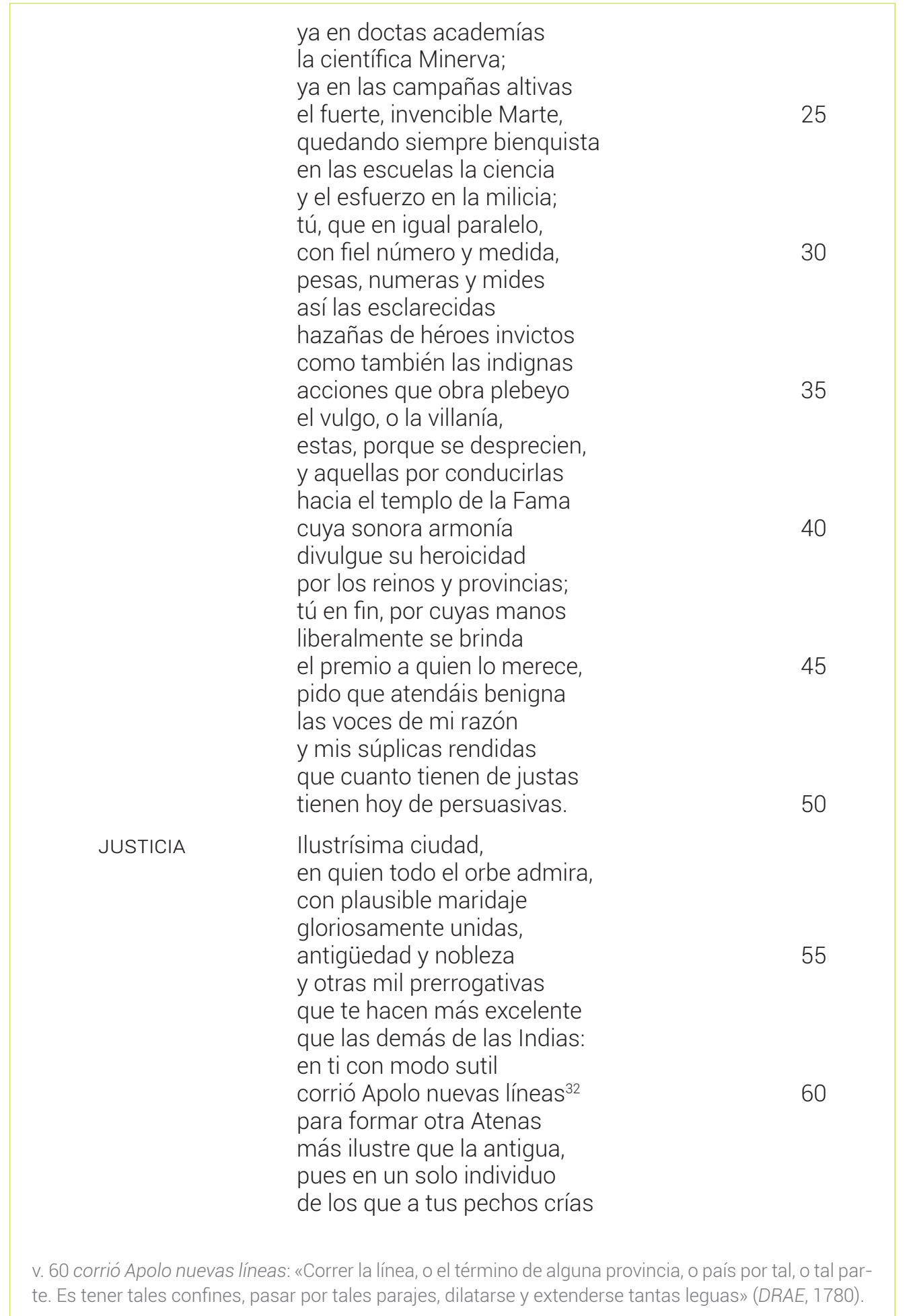


has producido, fecunda

de bien fundadas doctrinas,

los siete sabios de Grecia.

En ti Pomona divina

el paraíso terrenal

plantó, porque se diga

que eres cielo de la tierra,

de influencia tan exquisita

que, al mismo tiempo que amena

pingües frutos fertilizas

en tus espaciosos campos,

das aun a los muertos vida

con tus apacibles aires,

siendo cosa bien sabida

que en su suelo nadie muere

sino porque es precisa

condición de lo mortal

tener término algún día;

por último, en ti, Piura...

mas no quiero hacer prolija

narración de tu excelencia

y de tantas maravillas

que te hacen en todo grande

y cabal a toda vista,

porque no cabe en la voz

ni hay idioma que bien diga

las perfecciones que tienes

para ser tú la delicia

de todos los que dichosos

tu bello terreno pisan.

Solo me ofrezco a atender

a tu petición propicia

supuesto que la razón

dices que te patrocina:

bien puedes ya, sin temor

ni recelo, proferirla,

que te escucho con placer.

Sale el Placer vestido graciosamente.

PLACER Placer oí que decían,

$y$, en mentando al ruin de Roma,

hay por ahí una letrilla

que dice que asoma luego.

¿Qué mandan Vueseñorías? 


\begin{tabular}{|c|c|c|}
\hline JUSTICIA & $\begin{array}{l}\text { ¿Quién eres tú, que así dentras, } \\
\text { sin tener licencia mía, } \\
\text { hasta este sagrado alcázar } \\
\text { donde mi persona habita? }\end{array}$ & 110 \\
\hline PLACER & $\begin{array}{l}\text { Perdone Vuesamerced, } \\
\text { que no juzgué que tenían } \\
\text { semejantes majestades } \\
\text { reglas de la compañía, } \\
\text { pues allí solo noté } \\
\text { no estaba persona viva } \\
\text { hasta que, habiendo tocado, } \\
\text { después de dos semanitas³3} \\
\text { oía le decían «dentre», } \\
\text { mas aquí no presumía } \\
\text { que se observase lo mismo. }\end{array}$ & 115 \\
\hline JUSTICIA & ¿Quién eres? & \\
\hline PLACER & $\begin{array}{l}\text { La preguntilla } \\
\text { me hace dar que discurrir; } \\
\text { que hay sentencias infinitas } \\
\text { acerca de quién soy yo. } \\
\text { Unos me llaman la dicha, } \\
\text { y no tienen razón estos } \\
\text { pues las dichas presumidas } \\
\text { se vienen siempre muy tarde } \\
\text { y yo por la mañanita } \\
\text { es cuando ejerzo mi oficio. } \\
\text { Hay otros que me apellidan } \\
\text { la recreación, el contento, } \\
\text { el pasatiempo, el buen día, } \\
\text { día de recibir plata, } \\
\text { o la mano de una niña } \\
\text { que tenga crecida dote. } \\
\text { Algunos me denominan } \\
\text { pascuas y carnestolendas, } \\
\text { el cacao cuando está fría } \\
\text { la mañana y el refresco } \\
\text { cuando en las tardes estivas } \\
\text { está muy ardiente Febo; } \\
\text { finalmente, recopilan } \\
\text { todas las cosas de gusto } \\
\text { y cuanto bueno imaginan } \\
\text { para bautizarme bien, }\end{array}$ & 140 \\
\hline
\end{tabular}


y con todo, aún no se explican, pues si me han de definir con definición estricta

llámenme el Placer y está descifrado ya el enigma. El Placer soy, pues, y vengo sin que toquen campanilla a gozar de esta función que, si no dicen mentira, es una de las mejores y siempre el hado me inclina a gozar de lo mejor.

PIURA

Pero mientras yo consiga lo que mi afecto pretende, lo que mi amor solicita, lo que pide la razón y el mérito a la Justicia, ha de callar el Placer.

Sí callaré, como en misa, aunque rabio por hablar.

PIURA

Sabrás, pues, bella Justicia, que aquel famoso Atlante en cuyos hombros estriba toda la eminente mole de aquesta grande provincia, que ese científico Apolo cuya gran sabiduría en cátedra de milagros lección de prodigios dicta, que ese superior ilustre y cabeza esclarecida de cuyos sacros influjos hoy mi gloria se origina, que el gran Valdivieso, en fin, en cuyo nombre se cifran las virtudes que lo ensalzan las prendas que lo subliman y todas las perfecciones que a competencia fabrican en su noble corazón (el alcázar donde habita el bello terno de gracias) es honrosa parte mía.

Como que es criado a mis pechos este héroe, pues obtenía 
de oficial real la plaza

que le concedió interina

el Gobierno de este reino,

sirviola por muchos días,

dando siempre grandes pruebas

de su talento y pericia

para desempeñar bien

cuantos cargos le confían.

Mas, llevado de razones

muy justas que lo movían,

arbitró el renunciarla

como, de hecho, la resigna

en mano de quien la obtuvo.

Apenas esto acaecía

cuando veis aquí que el Rey

por cédula lo confirma

en la plaza renunciada

y, lo que más es, le envía

merced de corregidor

con gracia tan inaudita

que previene a su virrey

lo consulte porque elija

entre el uno y otro cargo

el que quisiere ¡Oh, viva

el grande Carlos Tercero

que así premia y dignifica

sus muy leales vasallos!

Aquí entran ya mis fatigas

y aquí quiero que me escuches:

con las dos cédulas dichas,

vacilante está el discurso

de ese sabio, y si admita

el corregimiento duda

porque, como nunca aspira

sino solo a su quietud,

a buscar esta se aplica,

de que temo que resulte

deje el bastón que le brinda

el cielo por dicha nuestra

para que cual sol nos rija

con universal contento

de su patria. Así rendida,

mis súplicas interpongo

para que tú no permitas

que deje de gobernarnos,

que aunque a su humildad le sirva 
de carga y peso, es un peso

con que a todos nos alivias.

JUSTICIA He escuchado tu alegato,

mas, como no determina

mi tribunal cosa alguna

sin que primero sean oídas

razones de entrambas partes,

es fuerza [que] esté indecisa

la sentencia en tanto que pueda haber quien contradiga.

PIURA

Contradecir nadie puede mi razón, sino la envidia, que funda su sinrazón en que no se verifican según su intento las cosas, mas si esta intenta, atrevida, alegar hoy de contrario, ya vendrá quien la resista.

[Segundo acto]

Canta la música.

MÚSICA

Sal ya, Mérito, a ceñir con verde laurel tus sienes, que una corona triunfante la Justicia te previene.

Salen el Mérito y la Envidia.

MÉRITO

¿Una corona triunfante la Justicia me previene? ¿Qué decís, sonoras voces? Romped aquesos motetes que sumamente me agrada

MÚSICA que vencedor me celebren.

ENVIDIA No temas el combate con la Envidia, porque siempre, presidiendo la Justicia, es el Mérito el que vence.

Callad, voces lisonjeras; callad, ecos descorteses, que con fingidos aplausos pretendéis vanamente eclipsar del mismo sol 
los rayos más refulgentes.

¿Quién ha visto jamás, quién, que mi orgullo y valor ceden

al Mérito la victoria?

Cuando mi soberbia siempre se ha mantenido constante en su lugar, aunque esfuerce sus razones la razón, la Justicia sus poderes, el Mérito sus violencias, y aunque todo el mundo intente domar mi vana arrogancia y humillar mis altiveces.

PLACER Deseado he desde niño y aun antes de que lo fuese ver la cara de la Envidia porque, según la encarecen con elocuentes pinturas los retóricos Apeles, pensaba ver un demonio más feo doscientas veces que todos los diablos juntos $y$, si mis ojos no mienten, no es tan fiero este león, o es que tiene algún afeite en la cara, con que engaña; mas, sea como se fuere, me causa gran compasión cuando estoy viendo roerle ese viborón el pecho.

Oh necia, ¿quién te mete en sentir bienes ajenos si tú eres quien lo padeces? Pero, ¿cómo estoy hablando si prometí obediente el callarme como en misa? Dirán que soy mequetrefe; antes que lo digan, callo: prosigan vuesas mercedes. 
me has ganado algún triunfo o has quitado de mi frente una hoja de Peneo ${ }^{34}$ que con su pompa ennoblece y acredita mis hazañas? $Y$, si alguna vez hubieses conseguido algún trofeo del Mérito, es evidente habrá sido por faltar el equilibrio que siempre en sus sentencias Astrea observa constantemente, pero ahora que preside la Justicia, que prefiere y le da el primer lugar siempre a la razón, no esperes el salir tan victoriosa como has salido otras veces cuando se han atropellado divinas y humanas leyes.

ENVIDIA

Te engaña la presunción $y$ hace que no consideres cuántas veces me has mirado ocupando un eminente trono, donde pisé airosa, sin que alguno lo impidiese, las diademas más brillantes, los cetros más refulgentes de los más altos monarcas, de los más invictos reyes. ¿No te acuerdas que yo fui la que en el zafir celeste del querubín más excelso pisé la soberbia frente, sin que para liberarlo el mérito le valiese? ¿lgnoras que yo arrojé del paraíso terrestre a los primeros mortales, y a todos sus descendientes los entregué desde entonces al imperio de la muerte? ¿No sabes también... 
JUSTICIA

Callad,

que vanamente pretendes

con acciones tan vulgares

acreditarte de fuerte.

Nada de lo que has citado

hace el asunto presente;

pues lo que ahora en este recto

tribunal se controvierte

es si aquel esclarecido

varón, aquel excelente

sabio, a quien de justicia

los honores se le deben,

ha de admitir, o no

el gobierno que le viene

de esta ciudad y provincia.

Di tú lo que te parece,

y deja que sus razones

también el Mérito alegue.

PLACER Si he de decir la verdad, al Mérito pertenece hacer toda la función, porque de su parte tiene tanto que decir en loor de ese acreditado jefe, que, sin meter en cuenta el beneficio que viene a este noble vecindario de que sus causas sentencie un docto jurisperito sin que en ellas ya se mezcle con dictámenes errados tanto abogado zoquete, hablará por veinticuatro y no dirá cuanto puede. ¡Hay tal tentación de hablar teniendo voto solemne de callar como un novicio! Pues ya callo: hablen ustedes.

Hable el Mérito.

MÉRITO

Digo, pues, las razones que me mueven para que se resuelva que el gran Valdivieso debe quedarse con el gobierno que le brinda francamente 
el señor Carlos Tercero.

Son muchas, mas brevemente

procuraré referirlas:

en él se hallan, si se atiende,

con modo muy especial,

las prendas que se requieren

para ser buen superior,

pues la claridad que tiene

es tal que parece hoguera

su corazón, donde enciende

sus benévolos afectos,

que como flechas ardientes

que salen de aquel carcaj

encendido, nadie puede

dejar de amarlo, teniendo

torpe nota de rebelde.

Su prudencia es admirable,

pues acción ninguna emprende

ni ha ejecutado obra alguna

sin que primero la pese

en las balanzas más rectas

de la discreción, que fieles

enseñan cuál es la parte

a donde inclinarse debe.

Su mansedumbre y paciencia

es uno de los dos ejes

en que estriba su gobierno,

pues si alguna vez se enciende

de su gran celo la llama,

tiene tan pronta la nieve

de su invicto sufrimiento

que la extinga, o que la temple,

que bien se puede dudar

si es la nieve la que prende

esa llama, o si es el fuego

quien la enfría y la refresque.

Su sabiduría es notoria,

pues sabe todo viviente

que dos Audiencias le han dado

estrados, donde ha hecho verse

animada biblioteca

de los derechos y leyes.

En fin, él es un cumulo

de prendas muy excelentes,

desinteresado, atento,

compasivo, indulgente, 
cristiano, noble y amable

que sabe cómo se debe

guardar su fuero a cada uno,

sin que jamás atropelle

al pobre, por miserable,

ni al que no lo es, porque espere

gratificación, como hacen,

cuando son malos, los jueces.

Ved ahora, divina Astrea,

ved si en justicia conviene

que tan ínclito varón

que tanto aplauso merece,

nuestro corregidor sea,

sin que más pueda oponerse

la Envidia.

JUSTICIA

Vuestra razones

mi entendimiento convencen.

PLACER ¿Pues no habían de convencer

al más cerrado caletre?

Aunque no dudo que hay necios

que oscurecer pretenden

estas glorias de ese invicto

coronel, porque les duele...

Mas ya falté al silencio:

vuelvo a callar.

JUSTICIA

Pues, ¿qué tienes,

torpe Envidia, que oponer?

ENVIDIA

Oh, pese a mis altiveces,

a mis ojos, fascinantes,

todos los bienes ofenden.

No puedo ver sin furor

ni a la rosa en los vergeles,

ni al jazmín en los jardines,

ni a la azucena en las verdes

guarniciones de esmeraldas

sin que mi cólera intente

obscurecer sus candores,

extinguir sus refulgentes

incendios y marchitar

sus olorosas niñeces.

No puedo mirar sin saña

los vivientes ramilletes

que, girando en la alta esfera,

forman tan vistosamente 
sus primaveras de pluma

sin hacer que luego truequen

sus canciones armoniosas

con los trinados dolientes.

No puedo sufrir que corran

esas cristalinas fuentes

por alamedas y parques,

uniendo con lazo débil

de resplandeciente aljófar

los narcisos y claveles

sin hacer que sean del prado

triste llanto sus corrientes.

En fin, nada me contenta,

ni de Flora los tapetes

en los pensiles y huertos,

ni en la región transparente

esas escuadras canoras,

ni en este zafir terrestre

los cristales que lo adornan.

Todo me cansa y ofende,

todo me lastima y punza,

me despecha y entristece,

y mucho más los aplausos

de aquese héroe, de tal suerte

que los quisiera ocultar,

y que se desvaneciesen

porque el mundo no los viera

ni el cielo los conociese.

PLACER

¡Pues quedáramos lucidos!

Vaya a cardar, si esto quiere.

Antes ciegue que tal vea,

$y$ antes que lo haga, reviente.

(Entre paréntesis puse

esto que digo; no tiene

que censurarme ninguno).

JUSTICIA Nada tu furor convence,

nada tus iras alcanzan,

ni tus sinrazones mueven.

Del Mérito es la victoria,

solo el Mérito se lleve

los vítores del triunfo,

y esta ciudad los laureles

que ha conseguido, pidiendo

con la razón convincente

del Mérito, le conceda 
que el gran Valdivieso quede

en el solio que, afectuosos,

le exigieron finamente

tiempo ha, en sus corazones,

sus vecinos, sin que lleguen

a bajarlo de sus cimas

ni del tiempo los vaivenes

ni los traicioneros vuelcos

que da la fortuna aleve.

¡Ea, cantad la victoria

por el Mérito que vence!

[Acto tercero]

Canta la música.

MÚSICA

ENVIDIA
Con la corona triunfante

al Mérito le convida

la Justicia, y abatida

se ve la Envidia arrogante.

Ceñid, Mérito, ceñid

las sienes con el dichoso

laurel, pues tan venturoso

has salido de esta lid.

¿Qué espera mi presunción,

que no muere despechada,

viéndose tan ultrajada

y en tan rara confusión?

¿Que ha de vencer la razón

del Mérito? ¡Oh, quién pudiera

sin que el mundo lo entendiera,

arrancar de la memoria

ese aplauso, aquella gloria!

Por muy feliz me tuviera.

Ya esto no quiere mi suerte,

y al verme tan abatida,

si no hay remedio en la vida,

veré si le hallo en la muerte.

¿A morir voy? Lance fuerte.

¿La muerte quiero sufrir?

Mejor es, porque vivir

no se puede sin honor.

Venzamos, pues, el horror:

vamos, vamos a morir. 
PLACER

Aguarda, que te daré una receta excelente

para morir de repente... pero aburrida ${ }^{35}$ se fue, y, según lo que se ve, ella va dada al diablo. ¡Válgame el santo San Pablo, que no he de poder callar! Cuando me llego a catar, ya ha dos mil cosas que hablo.

MÉRITO

Vencí ya, divina Astrea, no tengo más que esperar: yo te vuelvo a consagrar este laurel que hermosea mis sienes para que sea segunda vez victorioso. Voy, pues, a gozar glorioso de tan feliz vencimiento, con el reconocimiento que te debo, el ser dichoso.

Vase.

JUSTICIA

Y yo, gran Piura, te doy repetidos parabienes

por esta gloria que obtienes de que partícipe soy. Goza feliz desde hoy, renovado el resplandor de tu buen corregidor, que te dedico propicia por que es así de justicia, que pronuncio sin favor.

PIURA

Yo, Justicia, agradecida de alcanzar en tu presencia tan favorable sentencia, y de haber sido atendida, humilde y reconocida a tu innata rectitud con toda la multitud que en mi gremio ${ }^{36}$ amante estrecho, te ofrezco en aras del pecho inciensos de gratitud. 
Vanse la ciudad de Piura y la Justicia.

PLACER Ya que me han dejado solo,

he de hablar aunque me maten,

que en días de tanto aplauso

de nada el silencio vale;

y así, déjenme charlar,

pero ha de ser en romance,

que no me puedo avenir

con la ley del consonante.

Digo, pues, ilustre jefe

y mi venerado Atlante

que me gozo tanto de

que tú gobiernes y mandes

esta ciudad y provincia,

que no acierto a explicarte

cuán grande es mi regocijo,

y lo mismo entiendo pase

a cada hijo de vecino,

porque aunque se juntasen

mil lenguas para decir

el júbilo que renace

en toda esta población

al tenerle como a padre,

nunca bien explicarían,

ni aun podrían dar señales,

del contento que rebosa

en los pechos amantes

de tus leales compatriotas,

que bien conocen y saben

aseguran su quietud

mientras tú los dominares,

sin temer ya los despechos,

abatimientos y ultrajes,

los odios y las pasiones

de una justicia arrogante

que tal vez tome la vara

solo para vengarse

o para oprimir al pobre

(que hay hombres tan infames,

que degeneran de serlo,

porque solo se complacen

cuando hacen mal a los prójimos).

Tú, ya se ve que no sabes

estas lecciones de la ira,

pues a todos es constante 
que amas tiernamente al pobre, $y$ al que no lo es, nunca le haces daño, porque no estudias estas máximas fatales que vienen de los infiernos. Así, no puede dudarse que has de ser el bien de todos, con exclusión de los males.

Goza pues, feliz, Piura, de juez tan apreciable rindiéndole los afectos que le debes como madre. Y tú, Valdivieso ilustre, goza también los altares de adoración que te ofrece en su pecho el paisanaje. Recibe aquestos festejos como pequeñas señales de quienes, con alma y vida, deseando están celebrarte. $Y$ vive sin contratiempo muchas y largas edades, como quiere tu fiel patria que a vuestras plantas yace. 
